\title{
Urdimento
}

\section{PIRANDELLO ENCENA SEI PERSONAGGI IN CERCA D'AUTORE}

\author{
Martha Ribeiro ${ }^{1}$
}

\section{Resumo}

A influência da cena sobre a dramaturgia pirandelliana se revela contundente com as profundas mudanças operadas pelo autor na tessitura da peça Seis Personagens à Procura do Autor. Nesta obra, ícone de sua dramaturgia, Pirandello realiza seu próprio experimento cênico. Trata-se de duas versões da mesma peça: o texto original de 1921 e a versão revista e corrigida da edição de 1925, um híbrido entre cena e escritura.

Palavras-chave: Luigi Pirandello, Seis Personagens à Procura do Autor, dramaturgia, cena.

\begin{abstract}
There are ultimately two versions of Pirandello's Six Characters in Search of an Author, the original text of 1921 and a revised and corrected edition of 1925, which is seen here as a hybrid of text and production. In this iconic work, Pirandello's production was experimental and the influence of production over Pirandellian dramaturgy was decisive as profound changes were made in the structure of the play.
\end{abstract}

Keywords: Luigi Pirandello, Six Characters in Seach of an Author, dramaturgy, production.

"Eu me transformei na marionete da minha paixão: o teatro.” Luigi Pirandello²
A idéia de fundar uma Companhia estável em Roma não foi propriamente de Pirandello, mas de seu filho Stefano Landi, Orio Vergani e de outros jovens intelectuais; entre os quais Massimo Bontempelli e Corrado Alvaro. O projeto teatro d'eccezione (como foi chamado inicialmente), idealizado em outubro de 1923, objetivava ser um celeiro para jovens autores e diretores teatrais. Era uma nova tipologia de companhia teatral que se firmava na época: guiadas por um dramaturgo-encenador, estas companhias contrastavam com o tipo dominante no panorama teatral italiano: companhias teatrais nômades e centralizadas na figura do ator. Convocado a aderir ao projeto, Pirandello não só irá patrociná-lo, como também se empenhará pessoalmente na fundação e na direção artística do novíssimo Teatro de Arte. Em 1925 declara:
${ }^{1}$ Martha Ribeiro é Doutora em Teoria e História Literária pela UNICAMP/IEL, com período sanduíche na Università di Torino/

Itália, é Mestre em Ciência da Arte pela UFF, diretora e pesquisadora teatral.

${ }^{2}$ En confidence, in Les Temps, Paris, 20 de julho de 1925. 


\section{Urdimento}

${ }^{3}$ Luigi Piradello, En confidence, in Le Temps, Paris, 20 de julho de 1925. Reportado por Alessandro D'Amico e Alessandro Tinterri, Pirandello capocomico: La compagnia del Teatro d'Arte di Roma, 1925-1928, Palermo, Sellerio, 1987: 5.

${ }^{4} \mathrm{Cf}$ Alessandro D’Amico e Alessandro Tinterri, Pirandello capocomico: La compagnia del Teatro d'Arte di Roma, 1925-1928, Palermo, Sellerio, 1987: 5.

${ }^{5} \mathrm{Cf}$ Leonardo Bragaglia, Carteggio PirandelloRuggeri, Fano, Biblioteca Comunale Federiciana, 1987:51. As cartas selecionadas correspondem aos anos de 1932 a 1936 (a última parte do texto entre aspas é uma citação de Pirandello). A declaração de Pirandello do teatro como "ato de vida" aparece na sua introdução ao La storia del teatro italiano de Silvio D’Amico (Milano, Bompiano, 1936: 26).
Para mim nãofoi suficiente escrever peças de teatro, fazendo-as serem representadas. Hoje sou diretor e encenador de uma Companhia dramática. Os senhores devem acreditar, ainda que seja absurdo ${ }^{3}$.

Por que absurdo? Precisamente porque Pirandello sempre sustentou em seus argumentos teóricos que o teatro não seria nada mais do que uma ilustração do texto dramático, e que o ator, por sua vez, seria um terceiro elemento incômodo, infelizmente indispensável, entre o poeta e o público. Então, porque se envolver tão de perto com o fenômeno cênico, fundando uma companhia teatral? Talvez para dar às suas obras uma "concepção" cênica mais próxima possível da autoral, já que o autor sempre deixou muito claro o seu descontentamento em relação ao teatro de sua época.

Em uma entrevista ao jornal L'Impero no dia 11 de abril de 1925, Pirandello declara que ele mesmo pretende encenar com sua companhia boa parte de suas peças, inclusive àquelas que ainda não tinham sido montadas, para que finalmente entendessem como ele desejaria que elas fossem representadas ${ }^{4}$. Mas, muito mais do que se "rebelar" contra a má interpretação de suas obras, suas atividades no Teatro de Arte foram uma escola para o dramaturgo. O diaa-dia do palco, o convívio diário com cenógrafos, eletricistas, técnicos e atores, deram ao escritor uma maior consciência cênica. Sobre este ponto escreve Leonardo Bragaglia:

Além de se rebelar contra os arbítrios de algumas encenações das próprias peças, pelas quais Luigi Pirandello, como "Teatro de Arte de Roma", se inventou "teatrólogo militante", encenador, dramaturgo e Poeta de Companhia, ele adquiriu consciência - noite após noite - da absoluta autonomia do Teatro, da Obra de Arte no Teatro, "que não é mais o trabalho de um escritor, que se pode sempre salvaguardar do resto, mas um ato de vida a se criar, instante por instante, com a adesão do público que se deve alegrar".

O primeiro trabalho do Maestro apresentado fora da Itália foi a obra-prima Sei personaggi in cerca d'autore; nada mais coerente com a alma pirandelliana se pensarmos que a última conseqüência da peça é uma declaração de falimento do teatro dramático. Apresentada em 18 de maio de 1925 no teatro Odescalchi, a peça seguiu em uma longa temporada de apresentações ao exterior (ao todo foram 13 cidades), com Marta Abba no papel da Enteada e Lamberto Picasso no papel do Pai, transformando-se no espetáculo-símbolo da companhia. A peça Sei personaggi se caracteriza por um produto concebido em etapas, e foi no Teatro Odescalchi, em 18 de maio de 1925, que a versão definitiva de Sei personaggi se concretizou. Conforme demonstrado pelos novos estudos pirandellianos, houve uma influência decisiva da cena sobre 


\section{Urdimento}

a escritura final. A partir do contato com os atores, das interferências da realidade cênica e da influência de outras encenações, Pirandello "editou" a nova versão do próprio texto. E não foram simples ajustes de melhoria nos diálogos, foram mudanças significativas, de ordem estrutural, isto é, foram mudanças relacionadas aos elementos e aos procedimentos de concepção do próprio texto: houve um considerável aumento das didascálias, que se enriqueceram com novas indicações sobre a movimentação, e mudanças na caracterização dos seis personagens, que assumem uma maquiagem mais acentuada, um pouco expressionista, com figurinos estilizados ${ }^{6}$.

Tinterri e D'Amico no livro Pirandello capocomico observam pelo menos três significativas mudanças para esta nova montagem de Sei personaggi, que contrastam com as famosas edições anteriores (os espetáculos de Berlim, Paris e Nova York; respectivamente Reinhardt, Pitoëff e Pemberton na direção): os seis personagens não surgem mais dos camarins, eles se apresentam pelas costas do público, e sobem no palco depois de atravessar toda a platéia. Sobre a escada que liga o palco e a platéia, se desenvolve um novo e agitado vaivém do Diretor. Ao final do espetáculo, a Enteada-Marta Abba sai de cena por este mesmo caminho, enquanto os outros personagens são reduzidos a silhuetas por trás do fundo transparente do palco. A versão final da peça se parece com um "caderno de direção", onde se podem reconhecer traços da encenação conduzida por Pirandello para o Odescalchi, analisa Tinterri, como a indicação das duas escadinhas que o dramaturgo mandou construir para a reforma do teatro e toda esta nova movimentação dos seis personagens e do Diretor ${ }^{7}$.

A sensação de potencialidade provocada pela aparição singular dos seis personagens, como personagens "vivas" abandonadas pelo autor, justifica a aprovação do autor. Mas para sua própria encenação, Pirandello preferiu substituir o elevador por uma solução mais simples, pois, segundo ele, numa entrevista a Léopold Lacour para a revista Comoedia de Paris, o cenário nunca deve chamar mais a atenção do espectador do que a obra em si. Fazê-los entrar pelo fundo da platéia e depois, aos olhos do público, fazê-los subir ao palco, proporciona uma maior aproximação entre a realidade e a ilusão teatral: rompendo com a fronteira palco/platéia não só se subverte a noção de quarta parede, como se cria um mecanismo de intensificação da "realidade" destes seis personagens, que, na concepção do autor, já nascem como personagens vivos. Não é que o autor desejasse, com este recurso, fazer dos seis personagens "pessoas humanas", muito pelo contrário, ele queria impor estes personagens como personagens vivos, signo de uma outra realidade, muito diferente da realidade humana e por isso mais verdadeiros. Os seis personagens não são um prolongamento da vida humana, como queria a estética naturalista, eles são um prolongamento do teatro, do teatro como vida; como categoricamente nos sugere a didascália de sua apresentação:

Dezembro $2008-N^{\circ} 11$

Pirandello encena Sei Personaggi in Cerca D'Autore. Martha Ribeiro.
${ }^{6}$ Tinterri e D’Amico no livro Pirandello capocomico observam que o texto usado por Pitoëff, traduzido por Crémieux da primeira edição, era muito diferente do que foi usado na encenação de Pirandello em 1925. E quanto a Reinhardt, diz os estudiosos, 0 encenador se serviu do texto como um copião, usando-o com plena liberdade. Sobre 0 uso do texto em Reinhardt consultar: Michael

Rössner, La fortuna di Pirandello in Germania e le missinscene di Max Reinhardt in Quaderni di teatro, n. 34, anno IX, Firenze, Vallecchi, novembre 1986: 40-53.

${ }^{7} \mathrm{Cf}$ Alessandro

Tinterri, Pirandello regista del suo teatro: 1925-1928, in Quaderni di teatro, n. 34, op. cit., pp. 54-64. 


\section{Urdimento}

${ }^{8}$ Luigi Pirandello, Seis personagens à procura do autor, in Pirandello do Teatro no Teatro. São Paulo: Perspectiva, 1999: 188.

${ }^{9}$ Para uma análise completa das mudanças operadas em Sei personaggi consultar Claudio Vicentini, Pirandello riscreve i Sei personaggi in cerca d'autore, in Pirandello, il disagio del teatro, Venezia, Marsilio editori, 1993: 73-117.

${ }^{10}$ L. Gillet, Deux pièces étrangères à Paris, in Revue des Deus Mondes, 01 mai 1923, p. 226. Reportado em Roberto Alonge, Le messinscene dei Sei personaggi in cerca d'autore, in Testo e messa in scena in Pirandello, Roma, La Nuova Italia Cientifica, 1986: 65.

${ }^{11}$ Roberto Alonge, Le messinscene dei Sei personaggi in cerca d'autore, in Testo e messa in scena in Pirandello, op. cit., p. 65-66.
As Personagens não deverão, com efeito, aparecer como fantasmas, mascomorealidadescriadas, elaborações imutáveis da fantasia e, portanto, mais reais e consistentes, do que a volúvel naturalidade dos Atores. As máscaras ajudarão a dar a impressão da figura construída por arte e imutavelmente fixada cada uma na expressão de seu próprio sentimento fundamental, que é o remorso para o Pai, a vingança para a Enteada, o desdém para o Filho, a dor para a Mãe, que terá lágrimas fixas de cera na lividez das olheiras e ao longo das faces, como as que se vêem nas imagens esculpidas e pintadas da Mater Dolorosa das igrejas. Os vestuários também deverão ser de tecidos e modelos especiais, sem extravagância, com pregas rígidas e volume quase estatuário ${ }^{8}$.

As mudanças no texto de Sei personaggi, cunhadas a partir das mediações oferecidas pelas encenações de Pitoëf e Reinhardt, e de sua própria experiência como encenador, são tão contundentes (ao ponto de Alessandro D'Amico afirmar que o texto original de 1921 e a versão revista e corrigida da edição de 1925 são na verdade duas versões da mesma peça) que não deixam dúvidas quanto à decisiva influência da cena sobre a escritura pirandelliana9 . Tomando o tex to como exemplo desta mútua influência entre cena e escritura na obra pirandelliana, examinemos, com um pouco mais de atenção, a encenação de Pitoëf de 10 de abril de 1923. Nesse espetáculo, como se sabe, os seis personagens chegam ao palco por um elevador, no monta carga de serviço do teatro, envolvidos por uma luz esverdeada. O impacto dramático desta aparição misteriosa sobre os espectadores foi enorme, e causou um grande frisson na crítica especializada. Esta aparição inusitada, revelando "figuras de outro mundo, pálidas, vestidas de negro, suspeitas, agitadas" - como observou maravilhado um crítico francês da época ${ }^{10}$-, foi uma genial intuição de Pitoëf que, por meio de uma ousada marcação cênica, soube dar a estas figuras, que se auto-apresentavam como personagens saídas da imaginação do autor, declarando-se entidades superiores, a força necessária para convencer o público de que realmente estavam diante de algo extraordinário:

Segundo o texto de 1921 os seis entram por uma "passagem do palco", a mesma pela qual chegam os atores da companhia. Pitoëf separa com um relevante símbolo os seus destinos; os personaggi, enquanto realidade extraterrestre, descem do alto, lentamente, como em um rito mágico de encarnação. Os veste completamente de preto para reforçar a contraposição, radicalizando até mesmo onde não foi previsto pelo autor (para Pirandello o Pai usa "calça clara e paletó escuro"; para Pitoëf está todo de preto). Há um grande esforço, da parte de Pitoëf, para tornar evidente o contraste entre estes dois universos diferentes e separados ${ }^{I I}$. 


\section{Urdimento}

Se inicialmente Pirandello se incomodou com a solução do elevador (observa-se que o dramaturgo ao demonstrar sua contrariedade ainda não tinha assistido ao espetáculo, do projeto artístico de Pitoëf só havia recebido notícias), em Paris, ao assistir a encenação, foi tomado imediatamente por um sentimento de fascínio: "Pitoëf havia atingido o núcleo da obra Pirandelliana e o havia desenvolvido em todas as suas articulações. Havia dado força e densidade ao encontro-desencontro entre o mundo da arte e o mundo dos homens"12. Fazer os seis personagens entrarem pela mesma porta dos atores não lhes dava a força necessária para se impor como uma realidade "superior", totalmente estranha àquela que se estabelece no plano ordinário do palco.

No entanto, a solução encontrada por Pitoëf criou uma atmosfera de irrealidade em torno aos seis personagens que absolutamente desagradava o dramaturgo, pois seu maior objetivo era provocar um efeito de desorientação pelo qual o espectador não conseguisse mais distinguir as circunstâncias reais do acontecimento fantástico. Como visto, a própria estrutura dramatúrgica utilizada, a fórmula do teatro no teatro, possibilita a criação de "coincidências" entre a circunstância material da representação e a situação imaginária descrita na obra, e o elemento permanente que oferece esta base, para a fusão do plano real e do plano fantástico, é justamente o palco real. A possibilidade de fusão entre o universo da realidade cotidiana do teatro e o mundo da criação fantástica se reforçaria se os seis personagens chegassem ao palco através da platéia, como criaturas "reais", absolutamente "vivos", mas "irrepresentáveis", já que feitos de uma outra matéria, inegavelmente superior ${ }^{13}$. Como escreve Vicentini, não é de se espantar que boa parte do público na ocasião da estréia italiana tenha gritado "manicomio! manicomio!" ${ }^{14}$ :

A própria configuração do trabalho, onde a construção dramatúrgica se move em direção contrária ao conteúdo explícito do texto, o esforço constante de ocultar, de confundir sobre o palco a distinção entre o plano da realidade material e o da criação fantástica, faziam da peça uma obra de difícil compreensão. [...] (a fórmula do teatro no teatro) produzia pontos de contato reais, onde a realidade fantástica da obra tende a coincidir com as condições materiais da encenação. [...] (o palco) se revela inesperadamente como o lugar privilegiado do encontro entre o reino da arte e o mundo da realidade material. O que na perspectiva teórica de Pirandello era uma heresia, mas também uma tentação irresistível ${ }^{15}$.

Como dissemos, a entrada dos seis personagens pelo fundo da platéia possui como conseqüência profunda a quebra da barreira entre palco e platéia, o que coloca Pirandello em sintonia com as experiências de vanguarda, na busca do transbordamento dos limites entre realidade e ficção. Lembramos
${ }^{12}$ Ibidem: 67.

${ }^{13} 0$ tema da autonomia dos personagens já se observa muito antes na narrativa pirandelliana, basta consultarmos a novela Personaggi, de 1906; La tragedia di un personaggio, de 1911 e Colloqui coi personaggi, de 1915.

${ }^{14} \mathrm{~A}$ expressão italiana manicomio acusa uma situação absurda, inverossímel

${ }^{15}$ Claudio Vicentini, Pirandello, il disagio del teatro, op. cit., p. 80-81. 


\section{Urdimento}

que a imposição feroz e implacável de separação entre palco e platéia como dois mundos distintos, se desenvolve somente a partir do final do século XIX, mais precisamente com Wagner, na idéia de que sobre o palco deve se manifestar o mundo ideal do mito, contraposto ao mundo real representado pela platéia. E que nada deve perturbar o espaço reservado à evocação fantástica. Para Zola e seus discípulos é também indispensável o rigor na separação entre palco e platéia, obviamente por motivos opostos ao de Wagner. Para Zola, o palco deve prolongar a vida, isto é, deve reproduzir exatamente a realidade cotidiana. Esta separação absoluta entre palco e platéia é também um instrumento de proteção à criação teatral, utilizada por encenadores como Stanislavski. Mas o recurso se mostra limitado no confronto com obras de épocas passadas, ou de outras formas de teatro que não o ocidental, que explicitamente sugerem uma ligação entre o público e a cena. Um passo para se perceber que a rígida divisão entre palco/platéia representava muito mais um problema do que uma solução, já que impedia o desenvolvimento de efeitos cênicos, de exploração de novos espaços e de novas espacialidades, impedindo principalmente a concreta introdução do espectador na ação desenvolvida sobre o palco. A explosão do espaço cênico, sua dissolução, se faz imediata, solicitando, em diferentes modos, com diferentes propostas, uma relação mais estreita entre o público e os atores.

Contemporaneamente aos reformadores teatrais, Pirandello tinha consciência da problemática da relação personagem-ator para a cena teatral e da necessidade de se estabelecer uma nítida separação entre as identidades; ponto nevrálgico de muitas das teorias cênicas ao início do século XX. No ensaio Illustratori, attori e traduttori de 1907 se verifica o engajamento do escritor na direção de uma separação total entre as partes, mas a linha de comunicação pretendida por Pirandello se dá entre o personagem e o espectador, sendo o ator nada além de um terceiro elemento incômodo na fruição da obra de arte. Embora a autonomia do personagem em relação ao ator seja reivindicada tanto teoricamente quanto poeticamente, isto é, no texto Sei personaggi in cerca d'autore é possível reconhecer os pressupostos do ensaio Illustratori, attori e traduttori, se constata em Pirandello uma nostalgia em relação ao mito da transparência. O uso da fórmula do teatro no teatro estabelece coincidências entre o mundo ficcional e o mundo real: o espaço descrito pelo drama é o mesmo espaço do palco real e os atores se duplicam em cena, representando eles mesmos: ou seja, atores.

Se existe a consciência da separação entre ator e personagem, para se atingir a autonomia da arte (que para Pirandello significava o personagem autônomo e vivo), na prática se verifica uma espécie de tentação em atingir com o teatro, a partir do personagem, aquela autenticidade profunda que a experiência cotidiana nos nega; inspiração que se pode catalogar como romântico-idealista. Aqui se verifica um duplo efeito provocador de uma tensão entre a forma dramática e o conteúdo do texto, pois enquanto o discurso dos 


\section{Urdimento}

seis personagens desenvolve o argumento de uma irremediável distância entre a cena (realidade material) e o texto (realidade fantástica), na forma utilizada, o teatro no teatro, se observa uma tentativa de recuperação daquela transparência perdida.

Na realidade, Pirandello não construiu uma nova forma dramática, alternativa ao drama burguês, ele na verdade tencionou esta tipologia dramatúrgica reconhecendo a diferença inconciliável entre drama e teatro, entre ator e personagem, sem, no entanto, abandonar a nostalgia utópica do mito da transparência, mas fazendo do corpo do ator não uma marionete, e sim um fantasma; mito que permeia não só Seipersonaggi, mas, implicitamente ou explicitamente, toda sua obra posterior. Se é possível falar de uma teoria atorial pirandelliana diremos que, ao inverso do naturalismo, mas de efeito semelhante, sua dramaturgia propõe a possessão do intérprete pelo personagem dramático. Não será o ator a entrar no personagem, mas o personagem a entrar no ator. $\mathrm{O}$ teatro como local privilegiado do encontro e do desencontro entre uma realidade superior - o personagem dramático - e o mundo material da cena, o ator. Palco onde se verifica ao mesmo tempo uma distância e uma ilusão de identificação, onde a cena oscila entre a ficção, a tentativa de representação, e a instalação do real, no momento da possessão utópica - do ator pelo personagem.

A recuperação da fórmula do teatro no teatro significou para Pirandello a possibilidade de restaurar a arte no mundo físico do teatro, e isto é o que o afasta das propostas destrutivas da vanguarda. Como analisa Vicentini, o dramaturgo secretamente produzia sobre o palco as condições para que o mundo fantástico da arte pudesse efetivamente se unir com a realidade da vida material. Quando o espetáculo termina, os personagens estão sozinhos em cena, projetados em "grandes e destacadas sombras", o que Pirandello está insinuando (e afirmando) é que estes seis personagens, vivos, pertencem ao teatro. Foi neste sentimento de pertencimento ao teatro que Pirandello soube ouvir a lição de Pitoëf. Escreve Alonge: o elevador usado pelo encenador parisiense é um elemento de serviço da cena, ele pertence ao teatro, não é um adereço, ou um elemento cenográfico, ele é real. Os personagens em Pitoëff descem sim para a terra, para o palco, mas o céu deles é também o teto do teatro: "Os personagens chegam (e partem) por meio de um percurso típico da maquinaria cênica; de qualquer modo pertencem ao teatro" ${ }^{16}$. E o teatro destes seis personagens não deve ser de forma alguma um teatro fechado nos limites da convenção mimética-representativa, não deve ser apenas a reprodução ou o reflexo da realidade cotidiana, ele é sobretudo produção. Em outras palavras, não é a vida cotidiana que fornece o modelo para o teatro reproduzir, ao contrário, é o teatro que produz os modelos para a vida. Como dito tantas vezes por Pirandello: "a arte pode antecipar a vida".

Dezembro 2008 - № 11

Pirandello encena Sei Personaggi in Cerca D’Autore. Martha Ribeiro.

\footnotetext{
${ }^{14}$ Roberto Alonge, Le messinscene dei Sei personaggi in cerca d'autore, in Testo e messa in scena in Pirandello, op. cit. p. 71.
} 


\section{Urdimento}

${ }^{15}$ PAVIS, Patrice. Le théâtre contemporain. Paris: Nathan, 2002.

${ }^{18} \mathrm{O}$ desenvolvimento do conceito de virtualidade cênica na escritura dramática pode ser consultado no meu artigo $A$ dramaturgia (en) cena: a escritura de uma teatralidade, Scripta, Curitiba: UNIANDRADE, $n^{\circ} 4$, 2006: 161-167.
A versão definitiva de Sei personaggi é o exemplo mais contundente de que a escritura textual é o produto de uma acumulação entre texto e cena. Como disse Patrice Pavis, a dramaturgia é a arte da composição de peças que levam em consideração a prática cênica e, completamos, ela só se realiza com e na presença de uma teatralidade anterior ${ }^{17}$. A cena influenciou a nova versão do texto Sei personaggi, mas a via inversa também existe: como dito por Alonge, a intuição de Pitoëf sobre o texto de Pirandello fez com que o encenador tocasse o núcleo de sua poética; ora, só podemos falar de intuição quando existe alguma coisa em estado latente para ser descoberta. Sendo assim, podemos dizer que a dramaturgia opera uma conjunção de elementos e de códigos cênicos que, operacionalizados em forma de escritura pelo dramaturgo propõe em si uma forma cênica virtual, ou seja, pré-existiria ao texto dramático uma idéia de representação. Compreendendo a dramaturgia enquanto a escritura de uma forma cênica virtual e, ao mesmo tempo, como um produto mediado por experiências cênicas anteriores, concluímos que o espetáculo Sei personaggi de Pirandello é, ao mesmo tempo, resposta a uma teatralidade anterior e a concretização em parte de uma forma cênica virtual latente no texto ${ }^{18}$.

Da forma cênica virtual à forma cênica concreta, um longo caminho se deve percorrer; e Pirandello, como encenador de si-mesmo, provavelmente não conseguiu realizar a risca aquilo que ele pensava do texto. Ainda que ele tenha escrito o texto ficcional, no momento em que ele o leva para o palco, este se abre para uma nova realidade. Diferentes elementos passam a interferir, como a luz, o espaço, a interpretação dos atores, e as próprias referências cênicas do encenador. Uma conjunção de fatores que inevitavelmente produzem novas direções e significados ao texto concebido e idealizado pelo escritor. A passagem da forma cênica virtual à forma cênica concreta é um curto-circuito entre vários mundos que se auto-influenciam: o mundo ficcional escrito pelo autor, o mundo de referência cênico e humano do encenador, o mundo dos atores e o mundo do palco. Não é nenhum absurdo constatar que diversos achados de Pitoëf foram absorvidos e adaptados por Pirandello para sua trupe. Como por exemplo, o uso de um piano, que não existia na edição original de 1921; o movimento de dança dos atores ao início do espetáculo, marcando o clima descompromissado e vivaz dos atores sem a presença do diretor; o grito que anuncia a chegada do diretor, como um sinal para o retorno da disciplina. Claro que mesmo absorvendo muitos aspectos da encenação de Pitoëf, Pirandello criou um espetáculo seu, a partir de suas próprias referências e experiências cênicas:

Pirandello metteur en scène define um modelo de espetáculo em difícil e frágil equilíbrio entre a tradição nórdica (de Pitoëf e de Reinhardt) e a tradição mediterrânea (essencialmente dos diretores 


\section{Urdimento}

italianos do segundo pós-guerra), entre a interpretação filosófica dos Sei personaggi e a sua releitura em chave realística. Desaparecido Pirandello, se perde a hereditariedade do Teatro de Arte, aquele admirável e problemático ponto de equilíbrio se rompe $e^{19}$.

O que Alonge observa não está muito longe do que Gramsci intuiu anos atrás: que sendo o teatro o terreno mais próprio de Pirandello, a expressão mais completa de sua personalidade, muito se perde separando Pirandello encenador de sua obra escrita. Recordemos as palavras do próprio Gramsci:

Quando Pirandello escreve um drama, não expressa "literariamente" (isto é, com palavras) senão um aspecto parcial de sua personalidade artística. Ele "deve" integrar "a redação literária" com sua obra de ensaiador e de diretor. O drama de Pirandello adquire toda a sua expressividade somente na medida em que a montagem for dirigida por Pirandello ensaiador, isto é, na medida em que Pirandello suscitar nos atores em questão uma determinada expressão teatral e na medida em que Pirandello diretor criar uma determinada relação estética entre o complexo humano que representará e o aparato material do palco. Ou seja, o teatro pirandelliano é estreitamente ligado à personalidade física do escritor e não apenas aos valores artístico-literários "escritos" .

A interferência mediterrânea se observa na crítica de Gabriel Bouissy ao espetáculo Sei personaggi: "Novamente, a companhia de M. Pirandello desprezando os efeitos complicados ou fantasmagóricos, procura pela expressão do homem, somente a pessoa humana, o aspecto, o rosto e a voz. Método essencialmente mediterrâneo" ${ }^{21}$. O equilíbrio alcançado por Pirandello encenador se encontra em sua preferência pela simplicidade da forma cênica e na busca pelo realismo na interpretação dos atores. É no contraste entre a atmosfera surreal do texto e a forma cênica realista que reside a riqueza de Pirandello: a história extraordinária de Sei personaggi se torna aos nossos olhos realmente possível. Sim, ela pertence ao sonho, à fantasia, mas, com a intervenção de seu método de trabalho, e na qualidade interpretativa dos atores envolvidos, aqueles fantásticos seis personagens (intrigantemente) ganham plausibilidade. Enquanto as montagens de Pitoëf e de Reinhardt se comprazem em dar aos seis personagens um vôo quimérico, reforçando a atmosfera de sonho, a montagem de Pirandello faz com que estes seis personagens se equilibrem entre o fantástico e o real. Os atores da companhia Teatro de Arte, especialmente Lamberto Picasso (o Pai) e Marta Abba (a Enteada), e aqui nos serviremos mais uma vez das observações de Gabriel Bouissy, dão aos personagens fictícios uma grande vida interior transformando-os em verdadeiros seres vivos "sombras que
${ }^{19}$ Roberto Alonge, Le messinscene dei Sei personaggi in cerca d'autore, in Testo e messa in scena in Pirandello, op. cit., p. 73.

${ }^{20}$ Antonio Gramsci, $O$ teatro de Pirandello, in Literatura e vida nacional. Rio de Janeiro: Civilização Brasileira, 1978: 59.

${ }^{21}$ Gabriel Bouissy, La Troupe italienne joue "Six personnages en quête d'un auteur", in Comoedia, 10 juillet 1925; reportado in Alessandro D’Amico e Tinterri in Pirandello Capocomico, op. cit: 143. 


\section{Urdimento}

${ }^{22}$ Ibidem: 144

${ }^{23}$ Roberto Alonge, Le messinscene dei Sei personaggi in cerca d'autore, in Testo e messa in scena in Pirandello, op. cit.: 72 .

${ }^{24}$ Luigi Pirandello, Seis personagens a procura do autor, in Pirandello do teatro no teatro, op. cit.: 238.

${ }^{25}$ Como observado por Alonge, as encenações do segundo pós-guerra, embora com todas as limitações, recuperaram em parte aquilo que Pirandello imaginou para 0 seu teatro. se transformam em homens pelo mistério da arte" e fazem com que os personagens reais (o Diretor e sua trupe) se revelem "nada mais do que marionetes, por sua deformação profissional" ${ }^{22}$.

Por este princípio Pirandello não poderia deixar de estranhar a solução de Marx Reinhardt proposta para o espetáculo de 30 de dezembro de 1924 na cidade de Berlim; escreve Alonge: "encenada sobre um fundo escuro para suscitar uma aura de mistério, foi capaz de fazer dos seis personagens fantasmas de um pesadelo, sombras evanescentes" ${ }^{\text {"23 }}$. Nada mais contrário aos desígnios do dramaturgo que, em sua encenação, acentuou nos seis personagens o aspecto concreto, realístico. Sem contar que para a Enteada, personagem de Marta Abba, delineou um perfil bem mais sensual do que aquele proposto na versão de 1921. A atriz, entre todas aquelas que até o momento tinham interpretado o papel, Vera Vergani, Ludmilla Pito'f, Franziska Kinz, foi a única que se apresentou com os braços nus e com uma saia que lhe deixava uma parte das pernas descoberta. É no contraste entre o argumento textual e a forma cênica que Pirandello se afasta tanto de Reinhardt quanto de Pitoëf. Acreditando no grito do Pai ao final do terceiro ato, "Que ficção qual nada! Realidade! Realidade, senhores! Realidade! ${ }^{24}$, , Pirandello faz da fantasia uma realidade mais viva, mais "real" do que a realidade falsa e artificial do mundo cotidiano.

Observa-se que o modelo de espetáculo proposto por Pirandello, em chave realística, só foi realmente absorvido no segundo pós-guerra, primeiramente com as encenações de Orazio Costa (entre 1946 e 1949), que se esforçou para libertar Sei personaggi do estigma cerebral, sofístico. E depois, seguindo nesta mesma direção, o espetáculo de Strehler, diretor do Piccolo Teatro di Milano, de $1953^{25}$. Pirandello não pôde assistir a estes espetáculos, e a insatisfação em ver sua obra-prima interpretada de forma filosófica, cerebral, em ver os seis personagens interpretados sem a devida humanidade, o acompanhou até o fim de sua vida. Mas uma carta escrita para Ruggero Ruggeri em setembro de 1936 (três meses antes de sua morte) coloca a questão em outros termos:

Gostaria que esta nova edição atualizasse inteiramente, ou pelo menos do melhor modo possivel, a visão que tive do trabalho quando o escrevi. Precisa se evitar o erro que sempre se comete: fazer os Personagens parecerem sombras ou fantasmas, em vez de fazê-los como entidades superiores e com grande força, porque "realidade criada", forma de arte fixa e imutável para sempre, quase estátuas, se comparados à mobilidade natural mutável e quase fluida dos atores. Para obter isto, é suficiente dar ao Diretor-ensaiador e aos cômicos (corifeo e coro) o máximo de movimento, uma vivacidade ora divertida ora assustada, com roupas leves e quase esvoaçantes; aos Personagens, em vez disto, uma poderosa imobilidade e uma expressão fixa, que certamente se conseguiria 


\section{Urdimento}

melhor com uma máscara ao estilo da tragédia grega. Máscaras novas, obviamente feitas por escultores, que expressassem o comportamento mais característico: o "remorso" para o Pai, a "vingança" para a Enteada, a "dor" para a Mãe, o "desprezo" para o Filho".

A carta demonstra um Pirandello sempre insatisfeito, sempre em busca de novas iluminações para sua obra-prima. E demonstra também que sua própria encenação, acentuadamente concreta e realista, não se guiou por estas idéias que sem dúvida nenhuma afastam os seis personagens de todo e qualquer aspecto humano vivo e verdadeiro. Sei personaggi é uma obra que atravessa o próprio tempo do autor, ela está presente em todas as diferentes fases do artista, cada mudança de perspectiva do dramaturgo em relação ao significado da arte em confronto com a vida, faz com que estas seis personagens adquiriram uma nova face, um novo modus. Sei personaggi é sempre o ponto de partida de Pirandello e seu eterno retorno. Na carta, o frágil equilíbrio entre o metafísico e o mediterrâneo, observado por Alonge, se rompe completamente em favor do aspecto metafísico. O seis personagens, explica o dramaturgo, são personagens trágicos, máscaras fixas que sofrem dores elementares, que mais parecem esculpidas em mármore (o uso das máscaras propõe a "desumanização" dos personagens, transformando-os em criaturas metafísicas). Já o coro que os assiste possui toda a fluidez, a leveza e a plasticidade das coisas que por natureza são mutáveis: são artistas do mundo, cheios de vida e feitos de carne. Uma declaração que revela a lição apreendida pelo dramaturgo em seus dez anos de convívio com o teatro e com a atriz Marta Abba: a obra de arte, ainda que perfeita, é privada de vida, enquanto o corpo do ator (da atriz) é vida, é movimento. É com os seis personagens que tudo termina e que tudo recomeça. Eles são a jornada de sua própria vida dentro do mundo da arte.

\section{Referências bibliográficas}

ALONGE, Roberto. La scrittura teatrale e le estetiche tra le due guerre. In: Pirandello e la drammaturgia tra le due guerre. A cura di Enzo Scrivano. Agrigento: Centro nazionale studi pirandelliani, 1985. p. 05-60.

Le messinscene dei Sei personaggi in cerca d'autore. In: Testo e Messa in Scena in Pirandello. A cura di Enzo Lauretta. Roma: La Nuova Italia Cientifica, 1986.

BRAGAGLIA, Leonardo (org). Carteggio Pirandello-Ruggeri. Fano: Biblioteca Comunale Federiciana, 1987.

BOUISSY, Gabriel. La Troupe italienne joue "Six personnages en quête d'un auteur". Comoedia, 10 juillet 1925 .

D’AMICO, Alessandro; TINTERRI, Alessandro. Pirandello capocomico: La compagnia del Teatro d'Arte di Roma, 1925-1928. Palermo: Sellerio, 1987.

Dezembro $2008-\mathrm{N}^{\circ} 11$

Pirandello encena Sei Personaggi in Cerca D’Autore. Martha Ribeiro.
${ }^{26}$ Reportado em Leonardo Bragaglia, Carteggio Pirandello

-Ruggeri, op. cit.: 55 (carta de 21 de setembro de 1936). 


\section{Urdimento}

GILLET, L. Deux pièces étrangères à Paris. In: Revue des Deus Mondes, o1 mai 1923.

GRAMSCI, Antonio. O teatro de Pirandello. In: Literatura e vida nacional. Trad. Carlos Nelson Coutinho. 2. ed. Rio de Janeiro: Civilização Brasileira, 1978.

GUINSBURG, Jacó (org). Pirandello: do teatro no teatro. São Paulo: Perspectiva, 1999.

MELDOLESI, Claudio. Mettere in scena Pirandello: il valore della trasmutabilitá. In: Fra Totò e Gadda, sei invenzioni sprecate dal teatro italiano. Roma: Bulzoni, 1987. p. 141-161.

PAVIS, Patrice. Le théâtre contemporain. Paris: Nathan, 2002.

PIRANDELLO, Luigi. Illustratori, attori e traduttori. In: Saggi, poesie e scritti varii, a cura di Manlio Lo Vecchio Musti. Vol.6, 2. ed. Milano: Mondadori, 1965. p. 209-224.

Prefácio do autor. In: Seis personagens à procura do autor. Trad. Elvira Rina Malerbi Ricci. São Paulo: Abril, 1977.

En confidence. Le Temps, Paris, 20 de julho de 1925.

RIBEIRO, Martha de Mello. Pirandello operador da personagem teatral: o humor nas máscaras discrepantes. 2003. 133 p. Dissertação (Mestrado em Ciência da Arte) - Instituto de Artes e Comunicação Social, Universidade Federal Fluminense, Niterói: RJ, 2003.

RÖSSER, Michael. La fortuna di Pirandello in Germania e le missinscene di Max Reinhardt. Quaderni di Teatro. Pirandello tra scritura e regia. Firenze, anno IX, n. 34, novembro de 1986.

TINTERRI, Alessandro. Pirandello regista del suo teatro: 1925-1928. In: Quaderni di Teatro, anno IX, n. 34, Firenze, Vallecchi, novembre 1986.

UBERSFELD, Anne. Lire le théâtre II: L'école du spectateur. Paris: Belin, 1996.

VICENTINI, Claudio. Pirandello. Il disagio del teatro. Venezia: Marsilio editori, 1993.

. Sei personaggi in cerca d'autore, il testo. In: Testo e Messain

Scena in Pirandello. A cura di Enzo Lauretta. Roma: La Nuova Italia Cientifica, 1986. p. 49-62. 